\title{
THE HISTOPATHOLOGICAL STUDY OF THE MITSUDA REACTION IN THE CASE OF THE TUBERCULOID LEPROSY. (PART 2)
}

\author{
Tokuzo Yokota
}

\author{
Nagashima Aiseien Lepra Sanatorium
}

(1) Observations were made on 15 specimens of biopsies obtained from 5 cases of tuberculoid leprosy, each taken from the cutaneous sites of Mitsuda reaction. The following results were obtained.

(2) Within the first three days after injection, an inflammation of the nonspecific, acute exsudative type was observed. Tuberculoid granulation was observed $8 \sim 14$ days after injection.

(3) It was observed that the injected bacilii were destroyed in the tissue earlier than in the neural cases.

(4) The allergic nature of the early reaction, Biingler and Fernandez has stated, could not be found from histopathological standpoint.

(5) The histopathological picture of Mitsuda reaction is the tuberculoid granulom caused by the destruction product of injected lepra bacilli.

(6) There are no essential difference between neural and tuberculoid leprosy from the view of histological manifestation of Mitsuda reaction.

\section{光田氏反応の怔理組織学的研究}

\section{第 2 報＼cjkstart結核様玨紋瀨の場令}

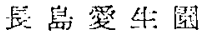

模开䈍兰

(昭和 28 公 4 月9)日受福)

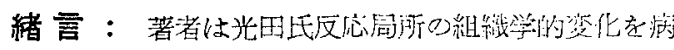

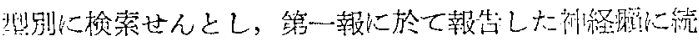

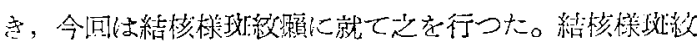

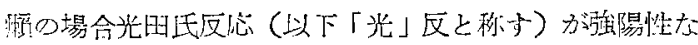

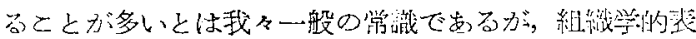

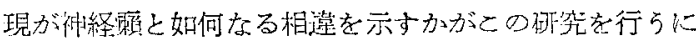
些つて深い與佅を引く点でする。

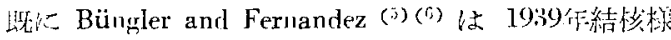

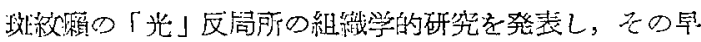

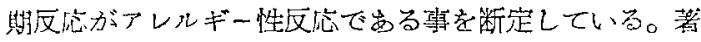
者は神経槞の場合：注射後 4 8 72 時間の所謂早期反忘 期に於ては被等の云万如き変化を認めず，注射 3 週後に

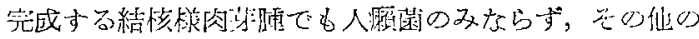

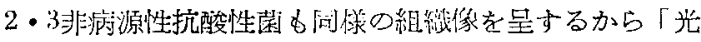

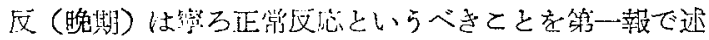

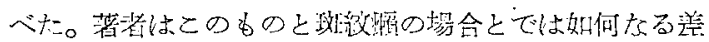

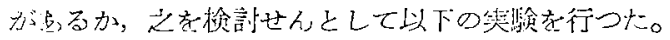

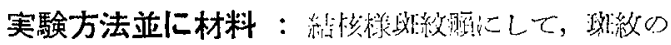

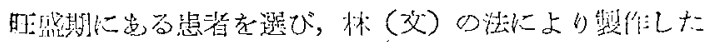

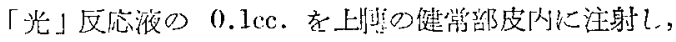

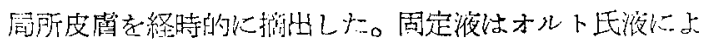
د†:。

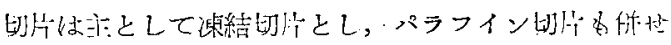
用いた。染色法はヂールへマトキシリンっへマトキシり ン・エオジン，ズダン]II，人マトキシリン，フイブリン

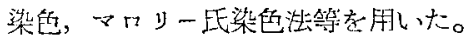

実験 成綪

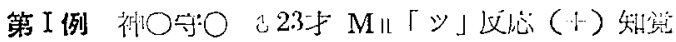


磨摩 $(-)$

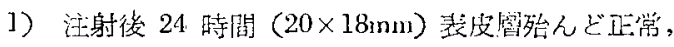
奌皮筞は乳頭血管克血，藷明，

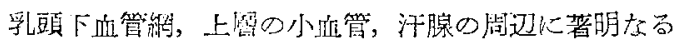

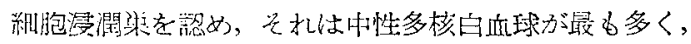
大淋区球様細胞，組維球栚細胞，少数の江オジン好性白 向球等より成る。

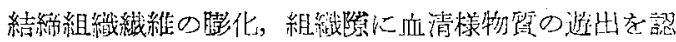
せ

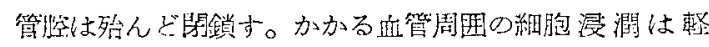
度。フイブリノイド乲性は認められず。注入藏は多核白

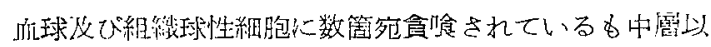

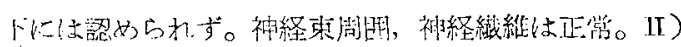
注射後 48 時間 $(18 \times 18 \mathrm{~mm})$ 表皮は蓝に肥曆するが，

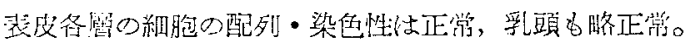

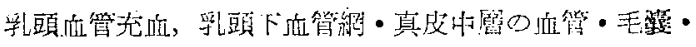

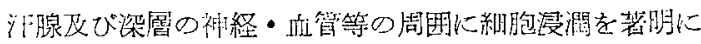

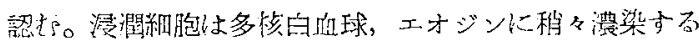

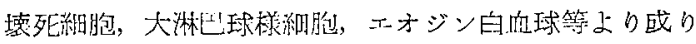

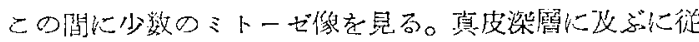

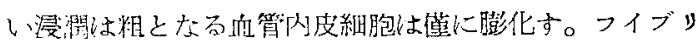

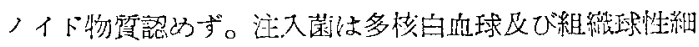

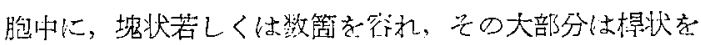

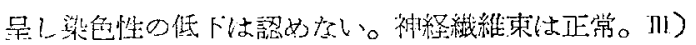

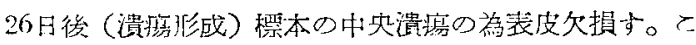

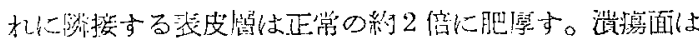

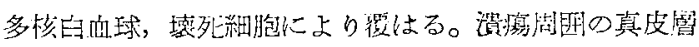

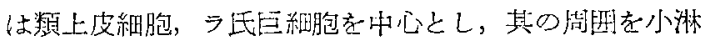

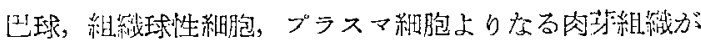

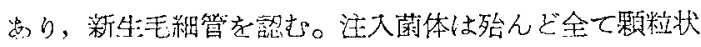
となり，チール氏液に弱く染る。結䋨絨細胞の增旗が真

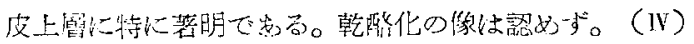

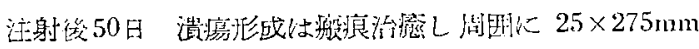

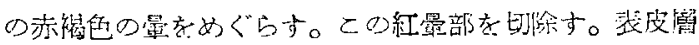

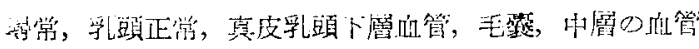

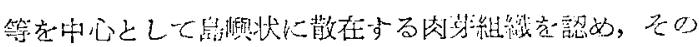

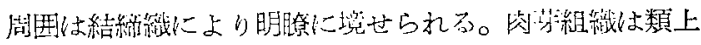
皮組胞ラ氏日租胞淋巴球ブラスマ細胞よりなる定型的結

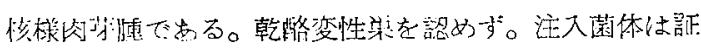

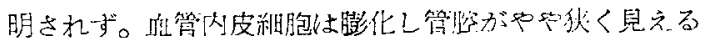
外著瓷を認めず。

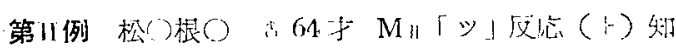

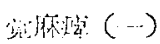

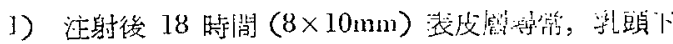

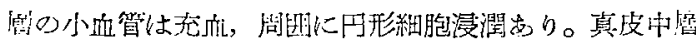

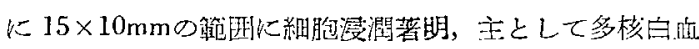

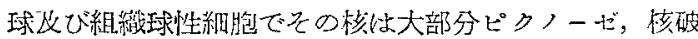

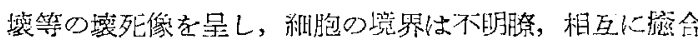
せる䘽を呈す。双エオジノ白血球を相当数認める。注入

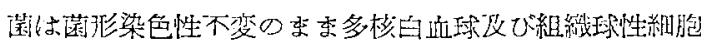

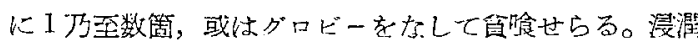

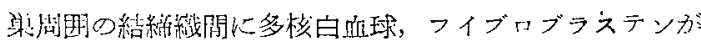

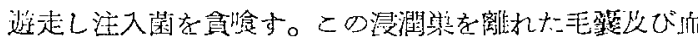

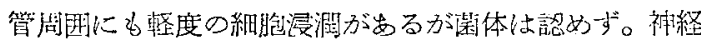

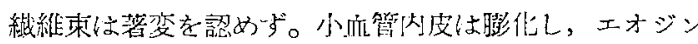

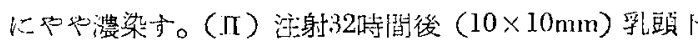

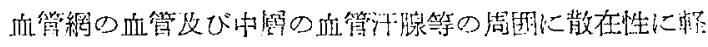

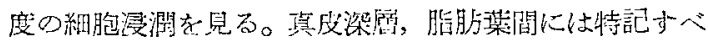

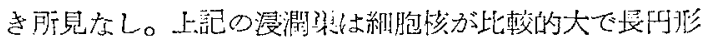

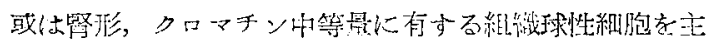

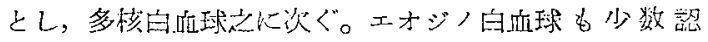

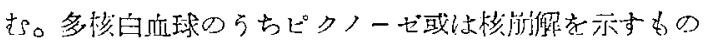

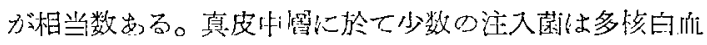

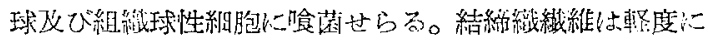
膨化L, 走行乱る。TiI) 注射後 20 日 $(10 \times 12 \mathrm{~mm})$ 真店

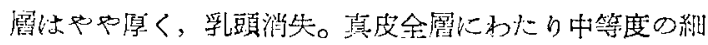

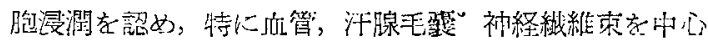

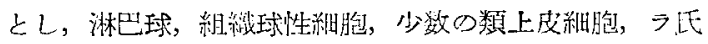

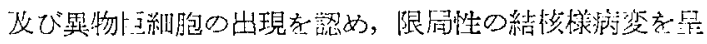

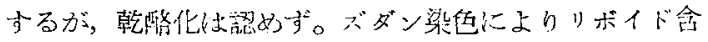

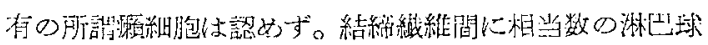

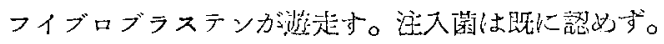

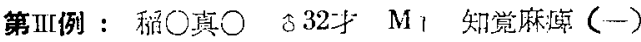
$\lceil \% 」 反 心(+)$

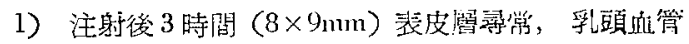

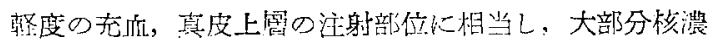

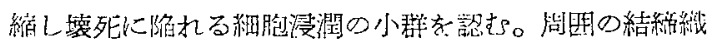

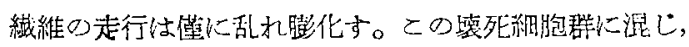

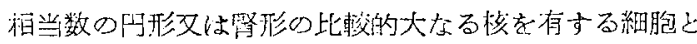

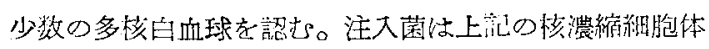

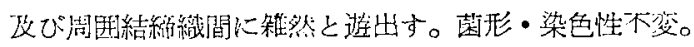

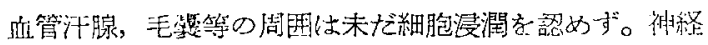

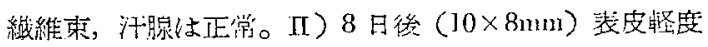

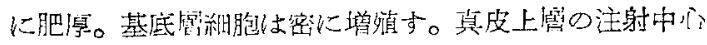

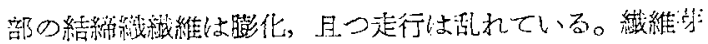

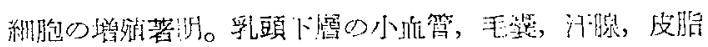

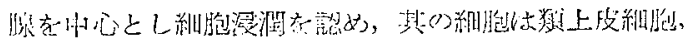

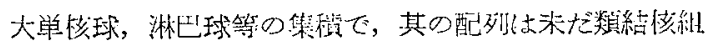


織を思わす如き像を認めず。浸潤細胞間にしばしばミト 一ゼの像を見る。類上皮細胞の集合埸所以核婊綰し原刓 筫はエオジンにやや濃染する部があるがフイブリン染色 によりフイブリノイド变性は㒛めない。注大菌を証明せ ず。ズダンエ染色によりりポイド变性細胞を見ず。

3) 注射後 15 日 $(8 \times 9 \mathrm{~mm})$ 或皮署：注射中块地心相 当する部は真没に生じた紛胞搌閶のたる押し上げられ，

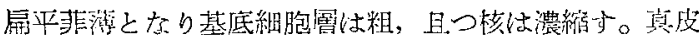

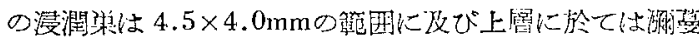

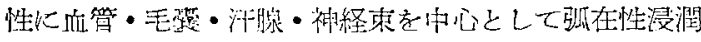

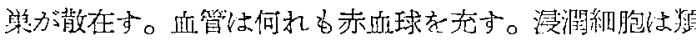

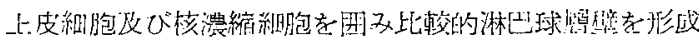

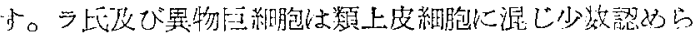
丸。真皮畃留に於ては類上皮細胞核のピクノーゼに陷

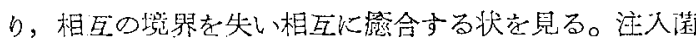

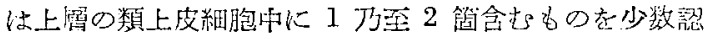

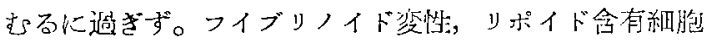
を晃ず。

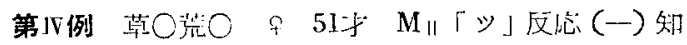
覚除算 (一)

1) 注的後 48 時間 $(8 \times 8 \mathrm{~mm})$ 上皮僅に肥厚。乳頭推

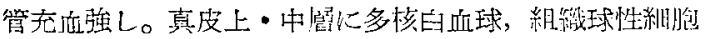

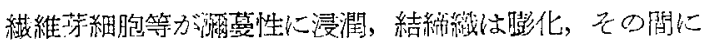

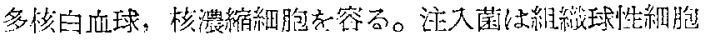

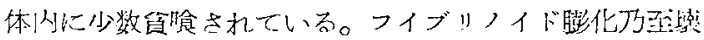

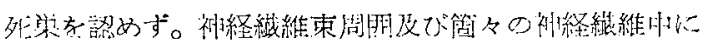

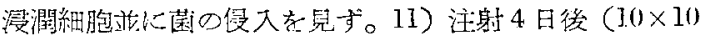

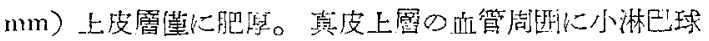

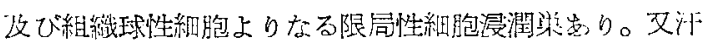

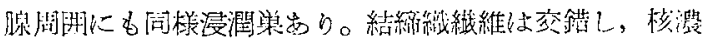

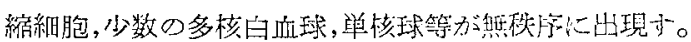

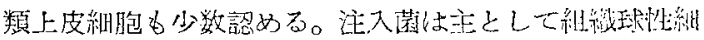

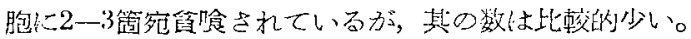

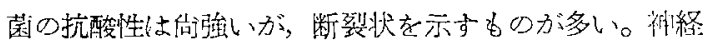

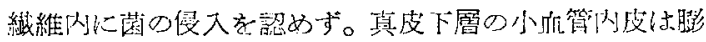

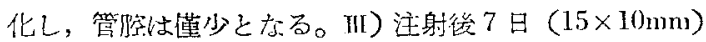

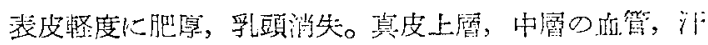

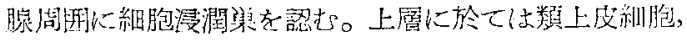

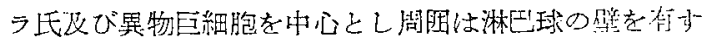

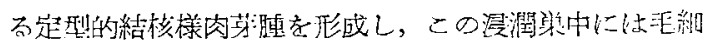

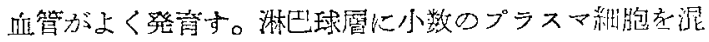

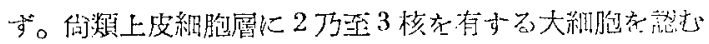

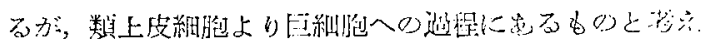

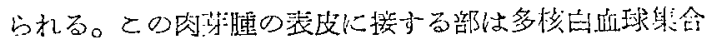

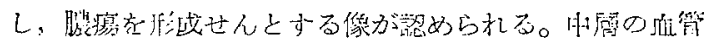

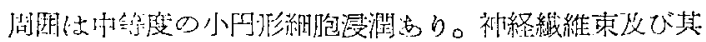

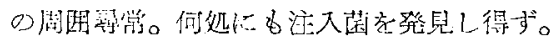

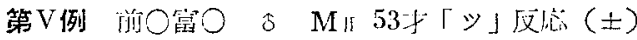

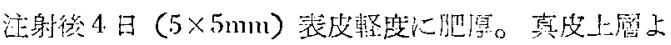

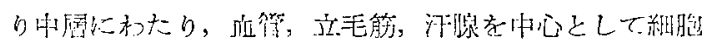

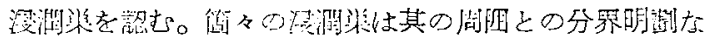

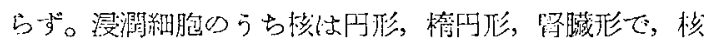

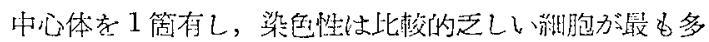

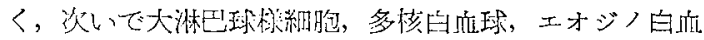

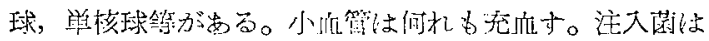

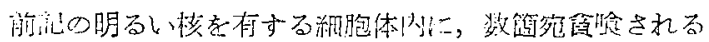

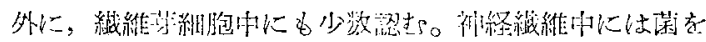

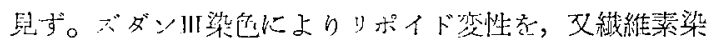

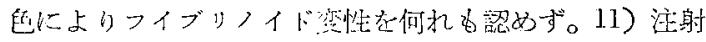

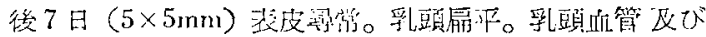

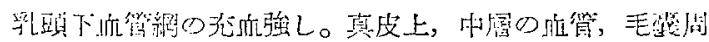

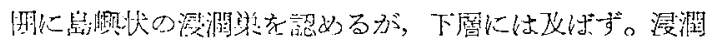

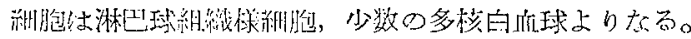

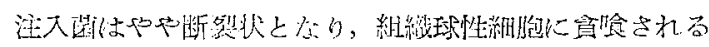

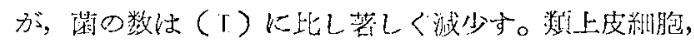

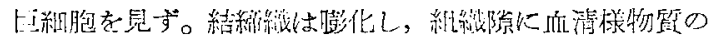

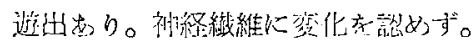

\section{総括並に考案}

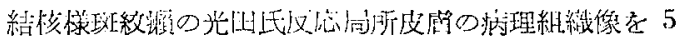

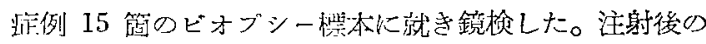

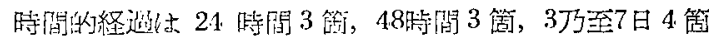

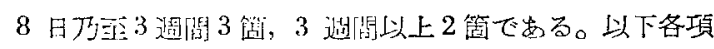
目に就㤩垩約を述ベ各。

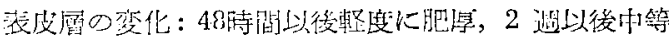

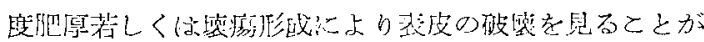

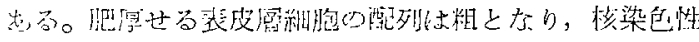

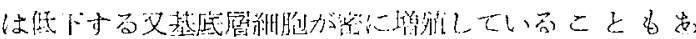
$z_{0}$

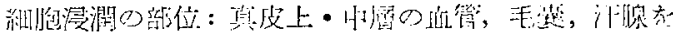

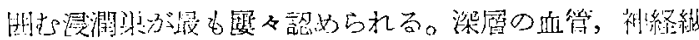
維京，脂肪望捎に以ぶことは少い。

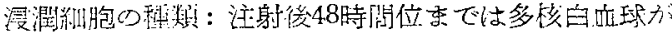

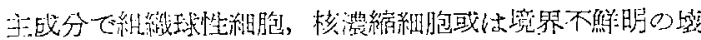

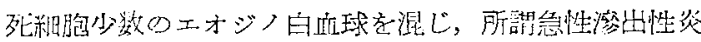

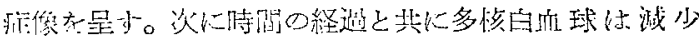

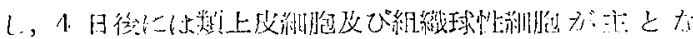

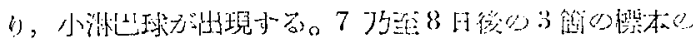




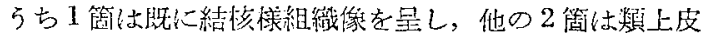

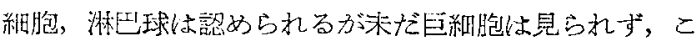
の期々於ては多核白血球老極く少数のみ認导。注射後 2

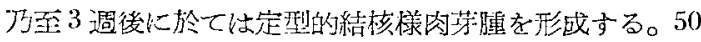
日後の 1 例化於ても佶結核梂組織像は認められる。結維

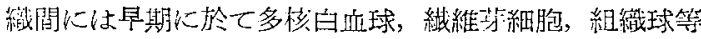

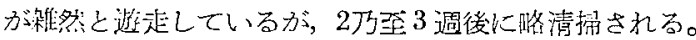

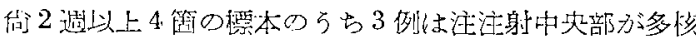

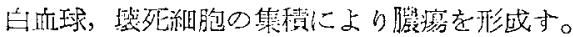

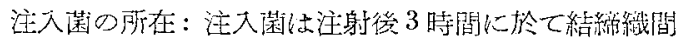

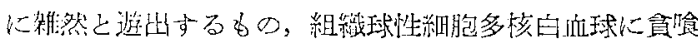

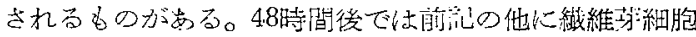

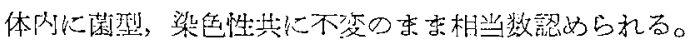

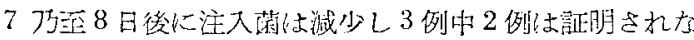
い。湖し 15 日後 20 日後の各1例代於て佮打少数なが

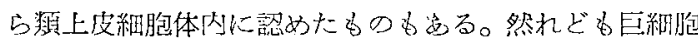
中にはは認ぬず。

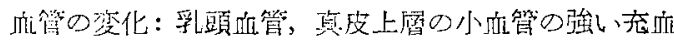
が短常認められるが新行停止の像はない。各層の折管队

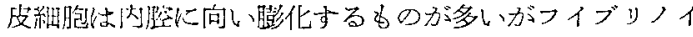

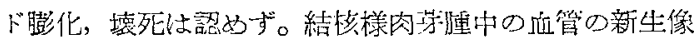

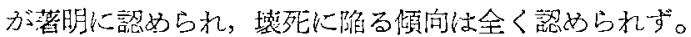

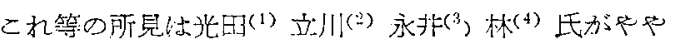
断片的化記载したものと䀩一致した成精で岕る。

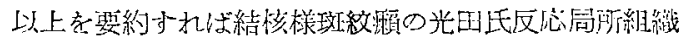
像と䘞経瀨の相異は，注射後 24 乃注 72 時间に壊死畨

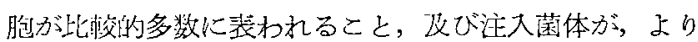

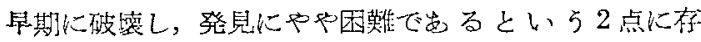
し，他化举ぐべきものがない。

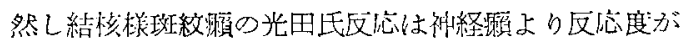
一般に强く，特に 48 時間後に於ける強陽性率は滛加心

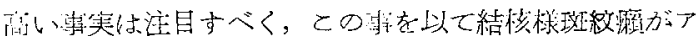
レルギー状能によりと考交られ，就中 Büngler and Fe

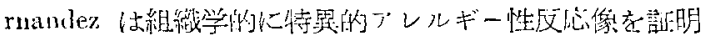

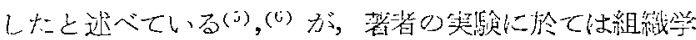
的裴現だけではナレルギー性反结と断短するに足る十分

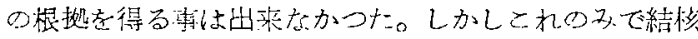

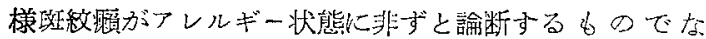

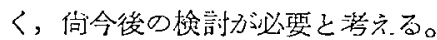

\section{結論}

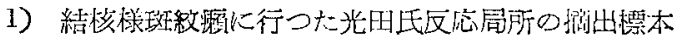

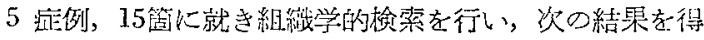
た。

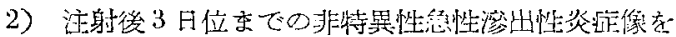

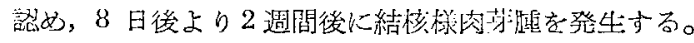

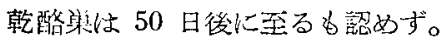

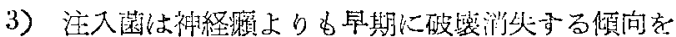
有する。

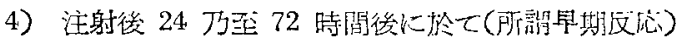

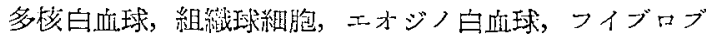

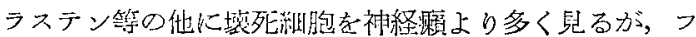
イブリノイド变性は認められない。

5）所謂早期反応が急性漻出性炎症の他にアレルギー 性組織像を呈するといら Büngler and Fernande' の毁 解には份㮝討を要する。

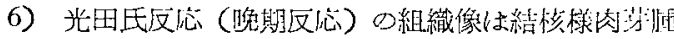
の泟成によつて䒾現される。

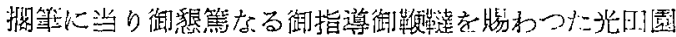

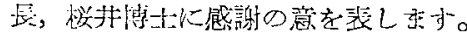

文献

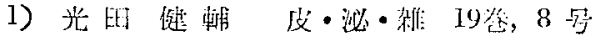
697 708真 1919从:

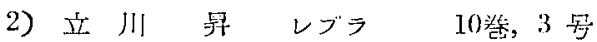
275 282页 1939

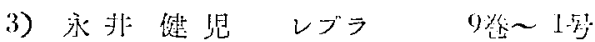
55 56 正 1938;:

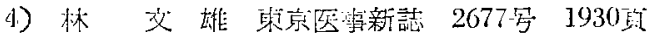

5) Büngler and Fernandez Virchow's Arch 305. 236 260 空 1939年

6) Büngler and Fernandez I. J. O. L.

Vol. 8 No. 1, 1 14劕 J940年 